\title{
Internal breast reduction surgery
}

\author{
Aristides Arellano-Huacuja ${ }^{1,2 *}$, Anja Arellano-Montalvo ${ }^{2}$ and Dafne Arellano-Montalvo ${ }^{2}$ \\ ${ }^{1}$ Department of Plastic and Reconstructive Surgery, Mexico \\ ${ }^{2}$ Dermatology and Aesthetic Surgery Clinic of Puebla, Mexico
}

\begin{abstract}
Nowadays, some people regret having a breast augmentation surgery, considering their implants oversized and not natural looking. However, the decision of having a reduction procedure is not easy, since it implies more skin scaring.

Some patients would like to reduce their implant dimensions about one or two sizes without having a new scar. Considering the skin and muscle previously involved, this represents a problem for the surgeon, who must perform a technique without long or bigger scars.

Therefore, we have developed a new technique, which allows us to perform an easy and efficient implant volume reduction avoiding the scar consequences of a breast lift surgery.
\end{abstract}

\section{Introduction}

\section{Patients}

To achieve this procedure, we require that the patient fulfils the following requirements:

- The implants must have been placed behind the pectoral muscle.

- The patient's skin should have a thick dermis layer.

- Pregnancy or drastic weight change might affect surgery's results.

- The nipple-areola complex may require a certain height reposition depending on the breast characteristics.

- The technique won't be helpful if the reduction is above two sizes.

\section{Technique}

To initiate, the breast area involved is infiltrated with a dilution of adrenaline and physiologic solution $(1: 10,000)$. The next step is to perform an incision right at the same place where the previous scar has been made, allowing us to remove the previous scar completely.

The tissue is dissected up to the implant until the implant is released, removed and exchanged for a smaller size. All the extra space left from the previous implant is sutured together in a circular fashion with Vicryl 1-0. Hemostasis is reviewed, and a smaller implant is inserted.

Continuing to close the pectoral muscle's fibrosis capsule with the superficial fascia of the chest wall. There is no need to perform a capsulotomy.

Sometimes we create a pocket under the breast tissue, over the fascia muscle.

The nipple-areola complex is repositioned $1-2 \mathrm{~cm}$ above the original place in order to live it higher. When needed, we suture the nipple-areola complex at the central or side level with Monocryl 3-0.

At least, the skin is closed with Histoacryl glow [1-3].

\section{Aftercare}

The use of post-surgical bra for 30 days is recommended, also back sleeping, general care of mammoplasty and avoiding any type of strength effort (Figures 1-14).

\section{Conclusion}

The proposed technique allows breast reduction with smaller implants without increasing the number and size of scars, which is very pleasant for the patients, and requires less recovery time.

It also allows to relocate the crease of the breast and maintain the implant and tissue in the right position.
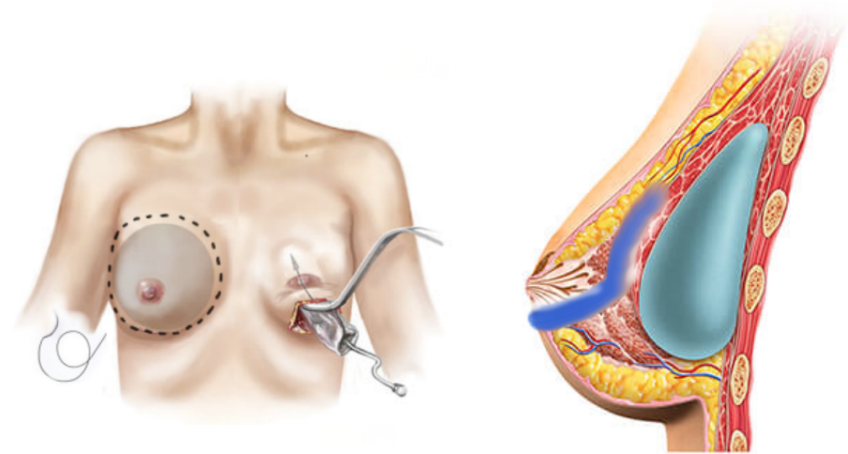

Figure 1. Working through the periareolar incision. We enter behind the subcutaneous tissue respecting the glad.

Correspondence to: Anja Arellano, Dermatologic and Aesthetic Surgery Clinic of Puebla, Laser Clinic Puebla, 20 Sur 2539 Col. Bella Vista. Zip Code 72500, Mexico, Tel: 00521222 9543542; E-mail: anja.arellano@hotmail.com

Key words: Facelift, Laser, Surgery, CO2, Erbium Yag, Aesthetic

Received: March 05, 2018; Accepted: March 22, 2018; Published: March 24, 2018 


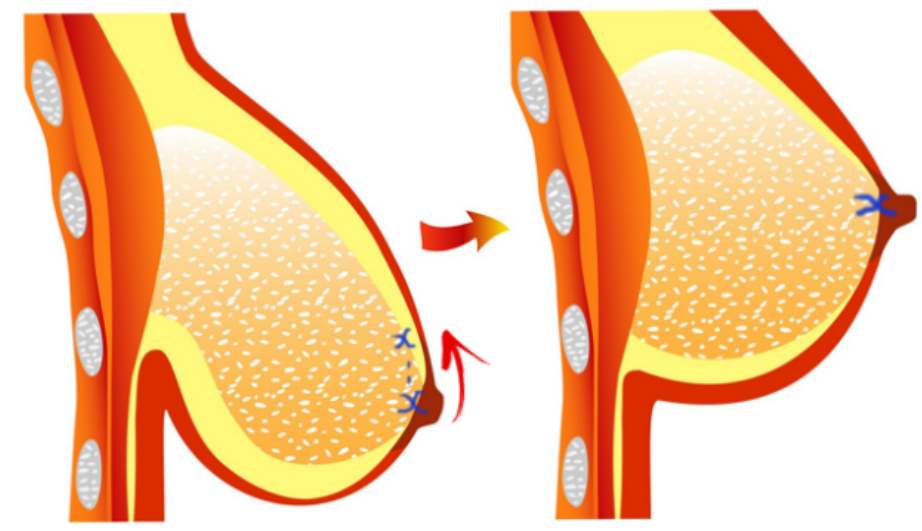

Figure 2. The nipple is sutured internally $1-2 \mathrm{~cm}$ above the current position. Suturing the subcutaneous tissue with the muscle fascia.

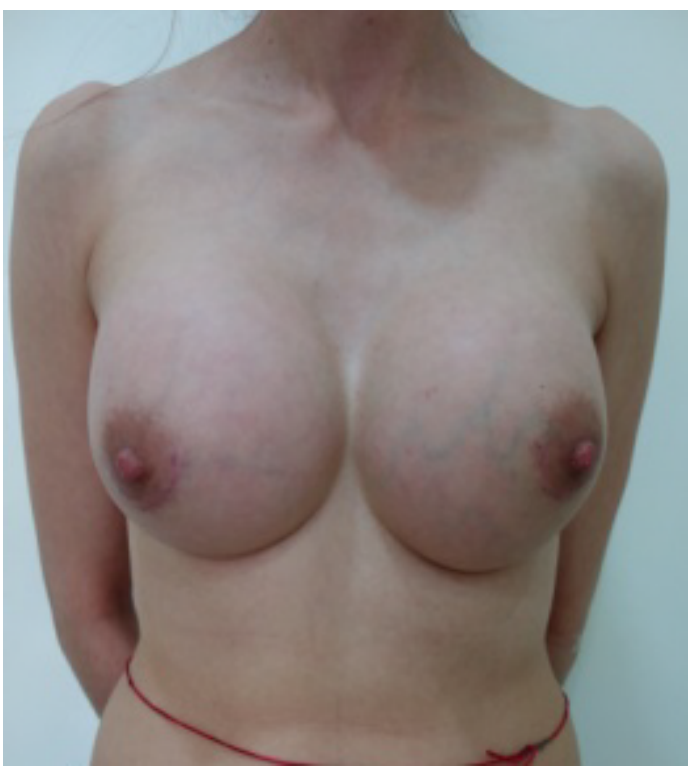

Figure 3. Before surgery $550 \mathrm{cc}$.

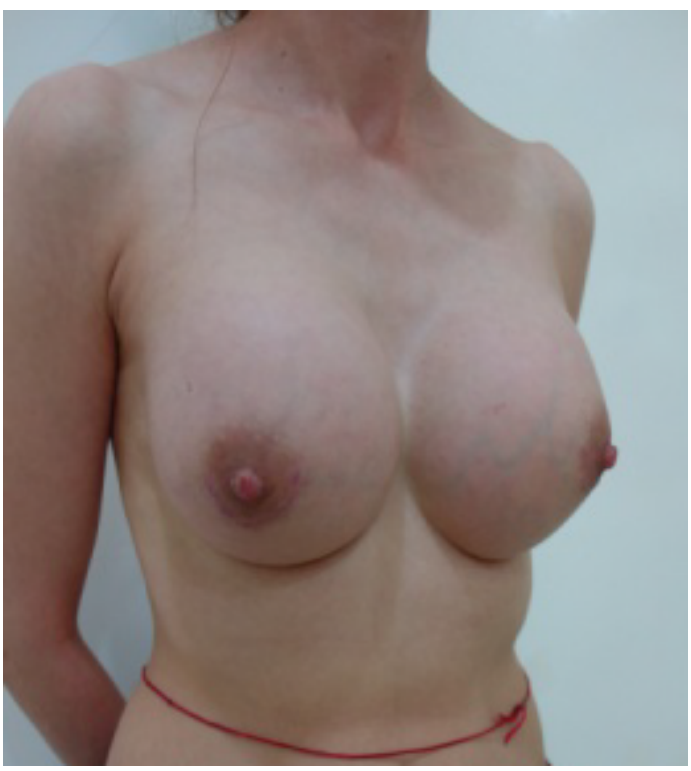

Figure 5. Before surgery $550 \mathrm{cc}$.

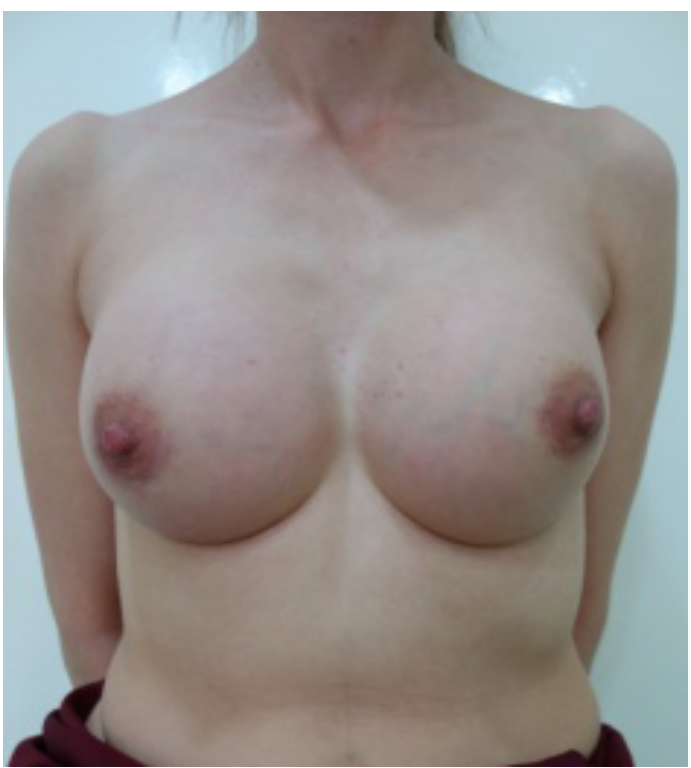

Figure 4. After surgery $370 \mathrm{cc}$.

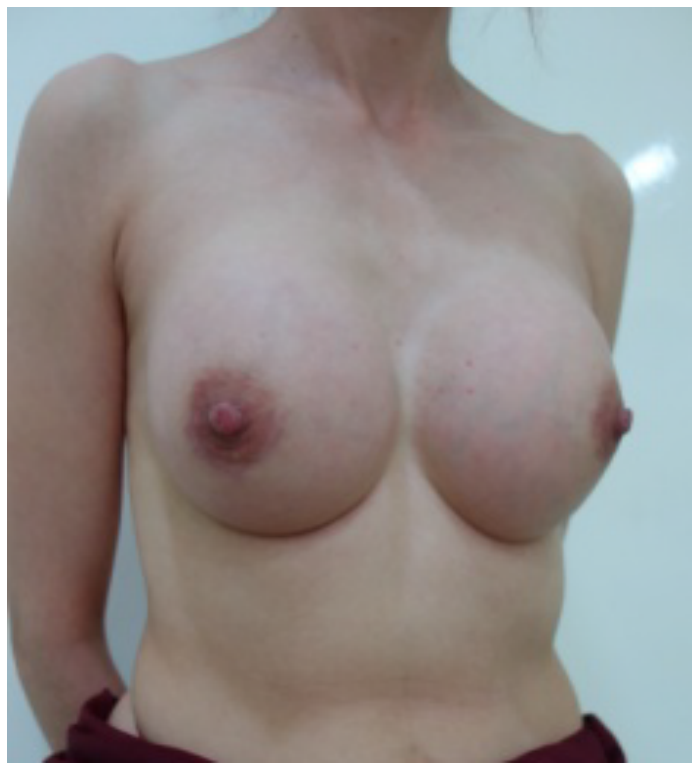

Figure 6. After surgery 370cc. 


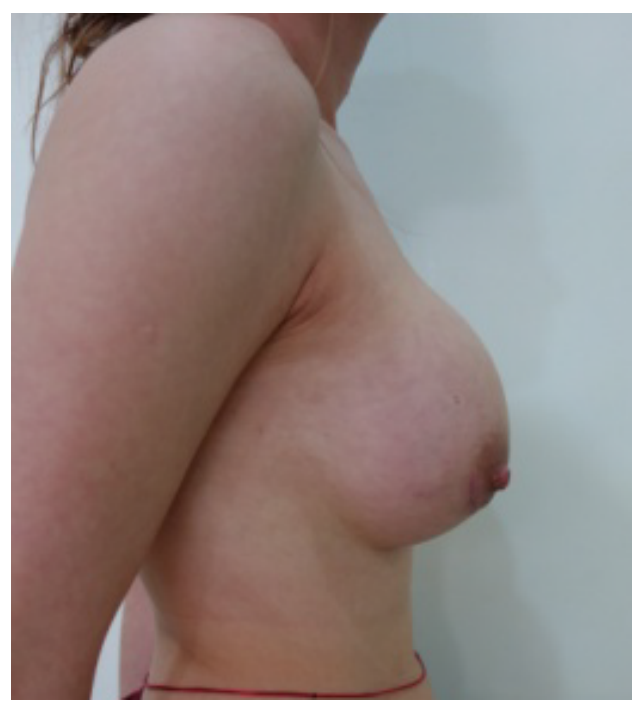

Figure 7. Before surgery $550 \mathrm{cc}$.

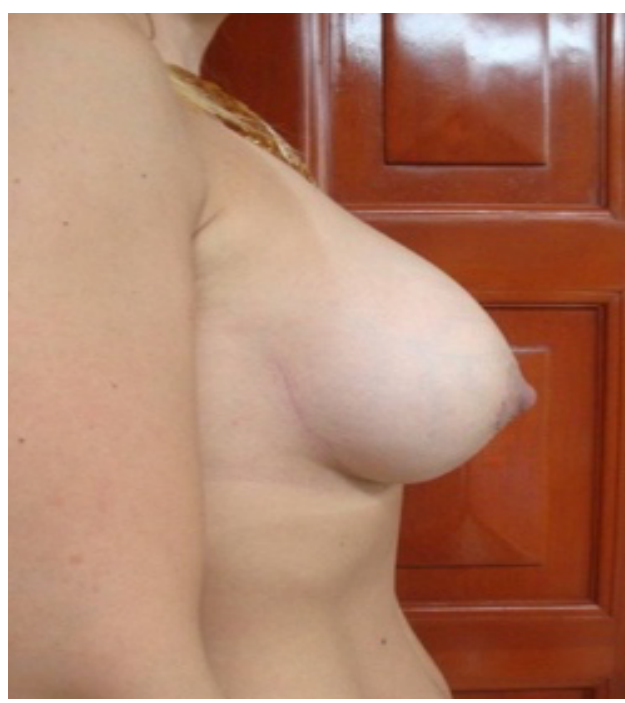

Figure 9. Before surgery $480 \mathrm{cc}$.

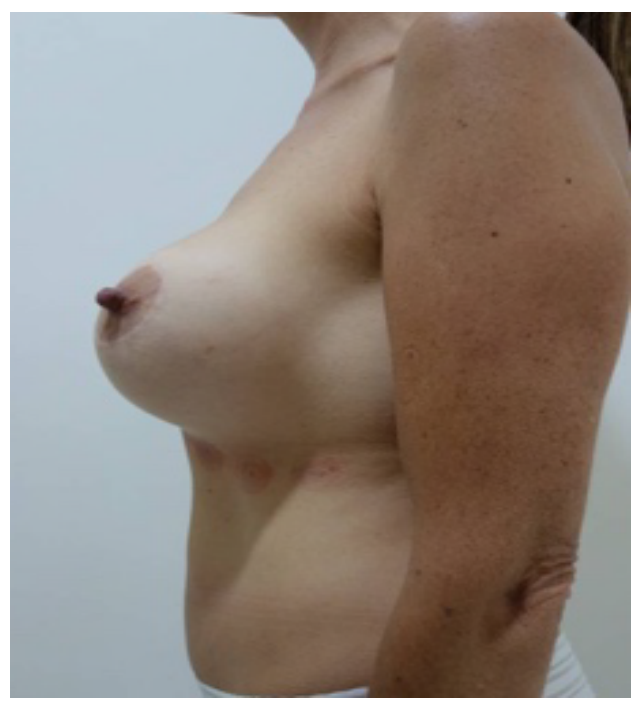

Figure 11. Before surgery $480 \mathrm{cc}$

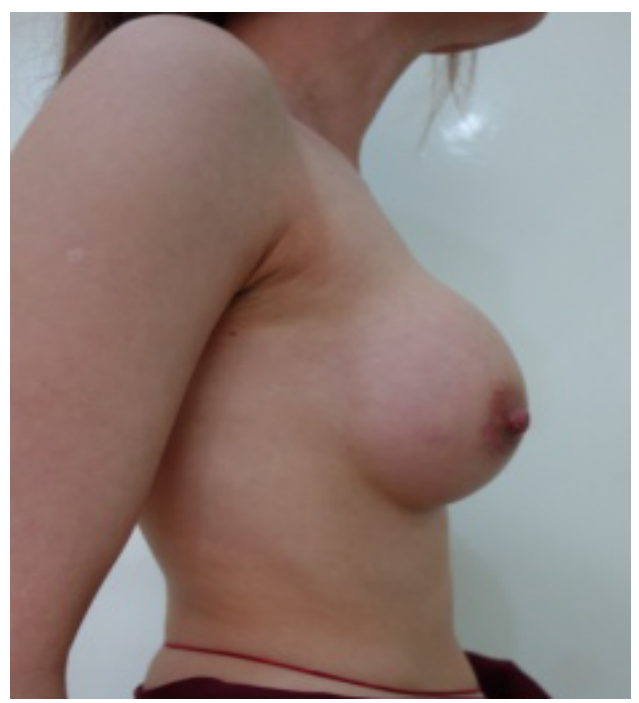

Figure 8. After surgery $370 \mathrm{cc}$.

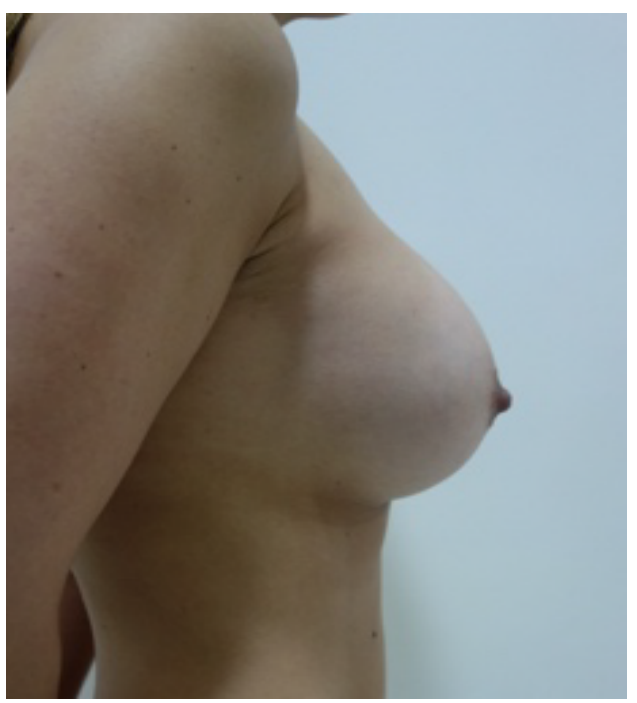

Figure 10. After surgery $370 \mathrm{cc}$.

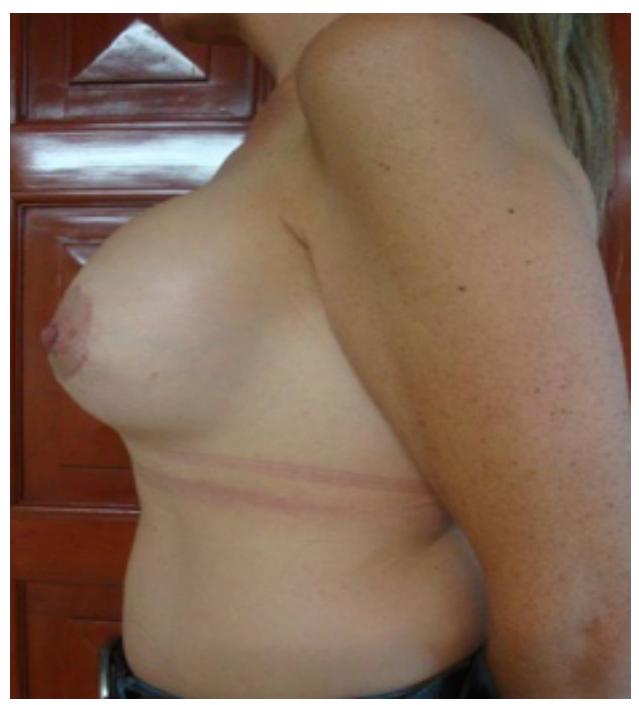

Figure 12. After surgery $370 \mathrm{cc}$. 


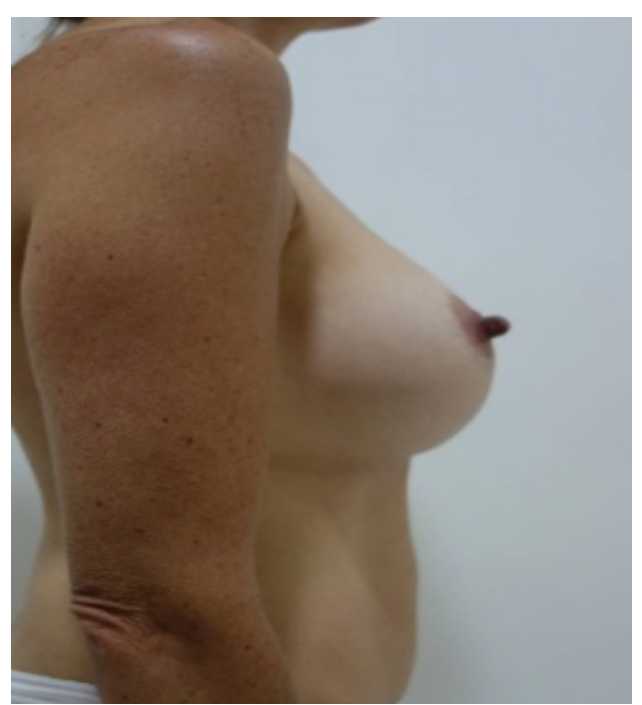

Figure 13. Before surgery $480 \mathrm{cc}$.

\section{Conflict of interest}

None

\section{Source of funding}

None

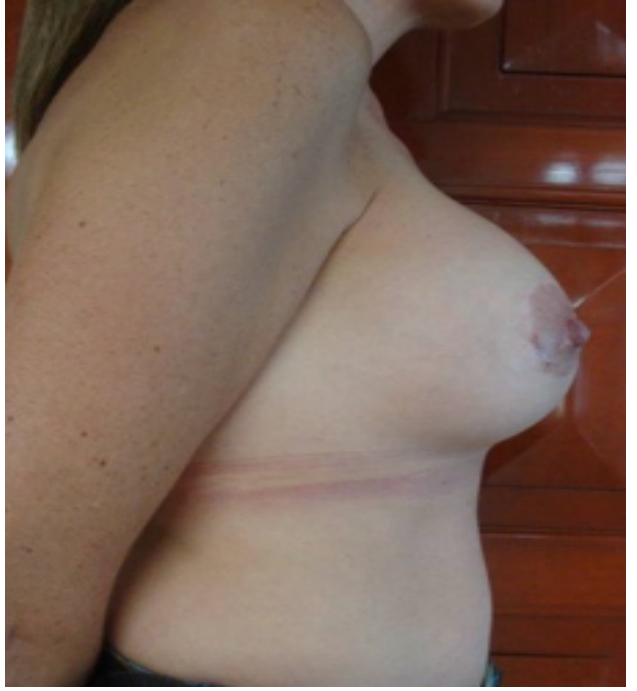

Figure 14. After surgery $370 \mathrm{cc}$.

\section{References}

1. Yépez Intriago M, Estrella Tejada P, Vélez Polit E (2013) Breast reduction with smaller scars for large mammary hypertrophy or gigantomastias. Cir plast iberolatinoam 39: 1-8.

2. Ali A, Zuleta-Bechara C, Vassaro V (2013) Dermoglandular support flap mastopexy with implants: technical Hammock. Cir plast Iberolatinoam 39: 361-368.

3. Nina L, Rocio M (2014) Aesthetic Breast Surgery. Rev Act Clin Med 47: 2503-2508.

Copyright: $(2018$ Arellano-Huacuja A. This is an open-access article distributed under the terms of the Creative Commons Attribution License, which permits unrestricted use, distribution, and reproduction in any medium, provided the original author and source are credited. 